\title{
National survey of UK endoscopists showing variation in diathermy practice for colonic polypectomy
}

\section{Ajay M Verma, Andrew P Chilton}

Department of Gastroenterology, Kettering General Hospital NHS Foundation Trust, Kettering, UK

\section{Correspondence to} Dr Ajay M Verma, Department of Gastroenterology, Kettering General Hospital NHS Foundation Trust, Kettering NN16 8UZ, UK; ajay.verma@nhs.net

Received 25 July 2018 Revised 12 September 2018 Accepted 16 September 2018 Published Online First 19 October 2018

\section{Check for updates}

(C) Author(s) (or their employer(s)) 2019. No commercial re-use. See rights and permissions. Published by BMJ.

To cite: Verma AM, Chilton AP Frontline Gastroenterology 2019;10:120-127.

\begin{abstract}
Introduction Diathermy practice in colonic polypectomy has a poor evidence base. We surveyed endoscopists across the UK to gain an insight in current diathermy practice.

Methods An eight-question survey was designed to be compact, easy to complete, while still capturing the relevant data. This national survey was circulated by the endoscopy committees of the British Society of Gastroenterology and Association of Coloproctology of Great Britain and Ireland.
\end{abstract}

Results The survey was open between February and October 2016. Analysis showed: (1) $250 / 348(71.8 \%)$ completed the full survey, 159 gastroenterologists (63.6\%), 36 surgeons $(14.4 \%), 34$ gastroenterology trainees $(13.6 \%)$, 21 others (8.4\%); (2) predominant use of coagulation current for small pedunculated polypectomy, high rates of cold snare polypectomy for small sessile polyps (right $43.2 \%$ $>$ left $34.4 \%$ ); (3) a combination of coagulation and cutting current, or Endo Cut, was most popular for larger polypectomy; (4) low use of Endo Cut mode irrespective of size/location of polyp (17.2\%-32.0\%); (5) 204/250 (81.6\%) used reduced current settings for right colon polypectomy; and (6) 208/250 (83.2\%) were confident on knowledge and use of diathermy. Conclusion This national survey exposes a wide variation in practice suggesting that colonoscopists employ diathermy modalities that they are comfortable with. As many complications are as direct result of thermal injury and polypectomy is the most frequent therapeutic intervention, appropriate training and formal guidance is lacking.

\section{INTRODUCTION}

Colonic polypectomy is the primary therapeutic procedure of colonic endoscopy and has many considered aspects. These include bowel preparation, optimised lesion detection, lesion recognition/ characterisation, polypectomy, post-polypectomy therapy, and polyp follow-up surveillance guidlines.

The wider community of endoscopists around the world has researched and evolved the recommendations for polypectomy, more so since the commencement and roll-out of Bowel Cancer Screening Programmes (BCSP). An example is that evidence for the use of adjuvant devices such as Endocuff Vision to improve lesion detection has been recently published. ${ }^{1}$ The British Society of Gastroenterology (BSG) guidelines on adenoma follow-up intervals are due to be renewed in 2018-2019.

It is an exciting time with larger complex polyps being removed using techniques such as endoscopic mucosal resection (EMR), endoscopic submucosal dissection, and hybrid variations of these techniques.

One aspect of polypectomy with a relatively poor evidence base is diathermy namely the appropriate techniques and settings to remove polyps safely while minimising the risks of thermal injury to the bowel (leading to a potentially fatal colonic perforation), and the dangerous complication of post-polypectomy bleeding. There is debate about when to use cold snare polypectomy techniques, and when employing diathermy, the appropriate use of; cutting current, coagulation current, and a combination/blend of the two.

Cold snare polypectomy has been shown in randomised controlled trials (RCTs), when compared with convention polypectomy with diathermy, to deliver higher rates of histologically complete removal for polyps $5 \mathrm{~mm}$ or less in size, the procedure time was also shorter. ${ }^{2}{ }^{3}$ RCTs have also shown lower rates of delayed post-polypectomy bleeding without thermal injury 
for polyps up to $10 \mathrm{~mm}$ in size when compared with conventional polypectomy with diathermy. ${ }^{45}$ Intraprocedural bleeding can occur but is self-limiting, not requiring intervention. ${ }^{6}$

Pure cutting current delivers effective incision with minimal thermal injury. ${ }^{78}$ However, it is associated with a significant increase in post-polypectomy bleeding $(\mathrm{OR}=6.95,95 \% \mathrm{CI} 4.42$ to 10.04$) .^{9}$ Pure coagulation current, which is frequently used by endoscopists, provides good levels of haemostasis. However, colonic thermal injury is a significant risk, ${ }^{7}$ this is of particular concern when performing right-sided polypectomy. ${ }^{8}$

Blended currents can be deployed manually (the operator using a combination of currents as they see fit), or increasingly popular - a microprocessor-controlled technique (such as Endo Cut) which uses both currents in a controlled blend which can be deployed by the operator pressing down on a single foot pedal. This is thought to deliver the best balance of current to resect a polyp, deliver haemostasis, and minimise thermal injury. ${ }^{10}$

The BSG and Association of Coloproctology of Great Britain and Ireland (ACGBI) guideline for the management of large non-pedunculated colorectal polyps suggests 'that a prolonged pure coagulation current should be avoided owing to an increased risk of delayed post-polypectomy bleeding and thermal tissue injury.' However, it is stated that the Grading of Recommendations, Assessment, Development and Evaluations evidence for this is low, and using a Delphi process, the strength of this recommendation is weak. ${ }^{11}$

The European Society of Gastrointestinal Endoscopy (ESGE) guidelines for colorectal polypectomy and EMR strongly recommend (based on high-quality evidence) cold snare polypectomy for polyps $5 \mathrm{~mm}$ or less in size. Stating 'this technique has high rate of complete resection, adequate tissue sampling for histology, and low complication rate.' For polyps $6-9 \mathrm{~mm}$ in size, cold snare polypectomy is suggested because of its 'superior safety profile', although evidence to compare with conventional polypectomy with diathermy is 'lacking' (moderate-quality evidence, weak recommendation). ${ }^{12}$

ESGE guidance suggests 'the use of a microprocessor-controlled electrocautery generator for polypectomy' but states this is based on low-quality evidence and a weak recommendation from the expert guideline authors. ESGE guidance recommends 'against using low power coagulation current for EMR because of the increased risk of post-procedural bleeding' and 'recommends against using pure cutting current for pedunculated polypectomy because of an increased risk of intraprocedural bleeding.' The quality of evidence for both recommendations is low, but strongly recommended. ${ }^{12}$

One could conclude that for polyps smaller than $10 \mathrm{~mm}$ in size, cold snare polypectomy should definitely be used for polyps $5 \mathrm{~mm}$ or less, and considered for polyps 6-9 $\mathrm{mm}$ is size. For larger polyps, the use of combination coagulation and cutting currents - ideally a microprocessor-controlled blend (such as Endo Cut) is thought to be optimal. However, giving the weaker evidence quality for diathermy, real-world practice may be variable.

An American survey of endoscopic practice in 2004 surveyed 198 endoscopists and found that blended current $(46 \%)$ and coagulation current $(46 \%)$ were most commonly used. ${ }^{13}$ Use of varied (4\%) and pure cutting current (3\%) was low. An Israeli survey in 2013 surveyed 100 endoscopists and found that $42 \%$ used a pure coagulation current, with $38 \%$ using blended current, and $20 \%$ using pure cutting current. ${ }^{14}$

A survey of endoscopists across the UK would reveal current diathermy practice for colonoscopy and give the wider endoscopy community an up-to-date insight into the challenges of standardising practice and training.

\section{METHODS}

We devised a simple eight question survey on diathermy practice; this was generated using the SurveyMonkey web-based platform (www.surverymonkey.co.uk).

The eight questions of the survey:

1. Which region do you work in?

(East of England, East Midlands, London, North-East, North-West, South Central, South-East, South-West, West Midlands, Yorkshire and Humber, Scotland, Wales, or Northern Ireland).

2. Which endoscopy grade/role?

(Physician trainee - independent, surgical trainee - independent, associate specialist/staff grade, consultant physician, consultant surgeon, or nurse endoscopist).

3. What type of endoscopy lists are provided in a typical working month?

(Symptomatic, bowel scope, BCSP colonoscopy. Select number between 0 and 9 , or $10+$ ).

4. What level of polypectomy do you undertake in a typical working month?

(Level 1 polypectomy - pedunculated and sessile, level 2 polypectomy - pedunculated and sessile, level 3 polypectomy. Select between $0-1,2-3,4-6+$ ).

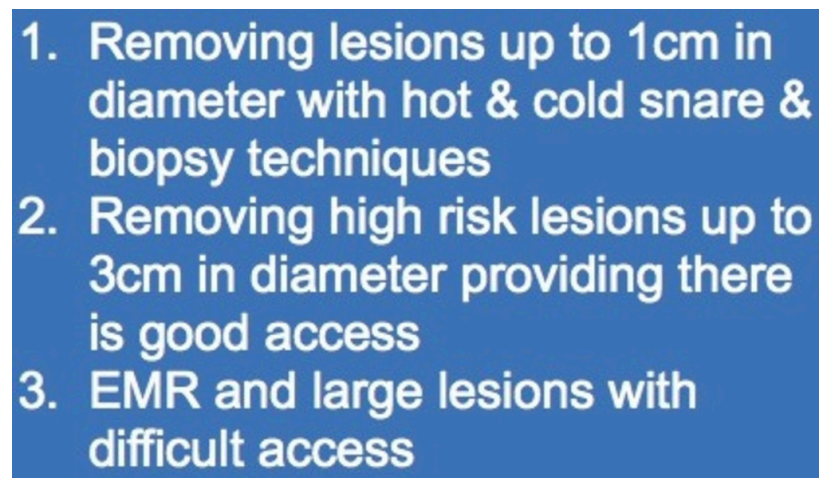

Figure 1 Polypectomy levels. EMR, endoscopic mucosal resection. 


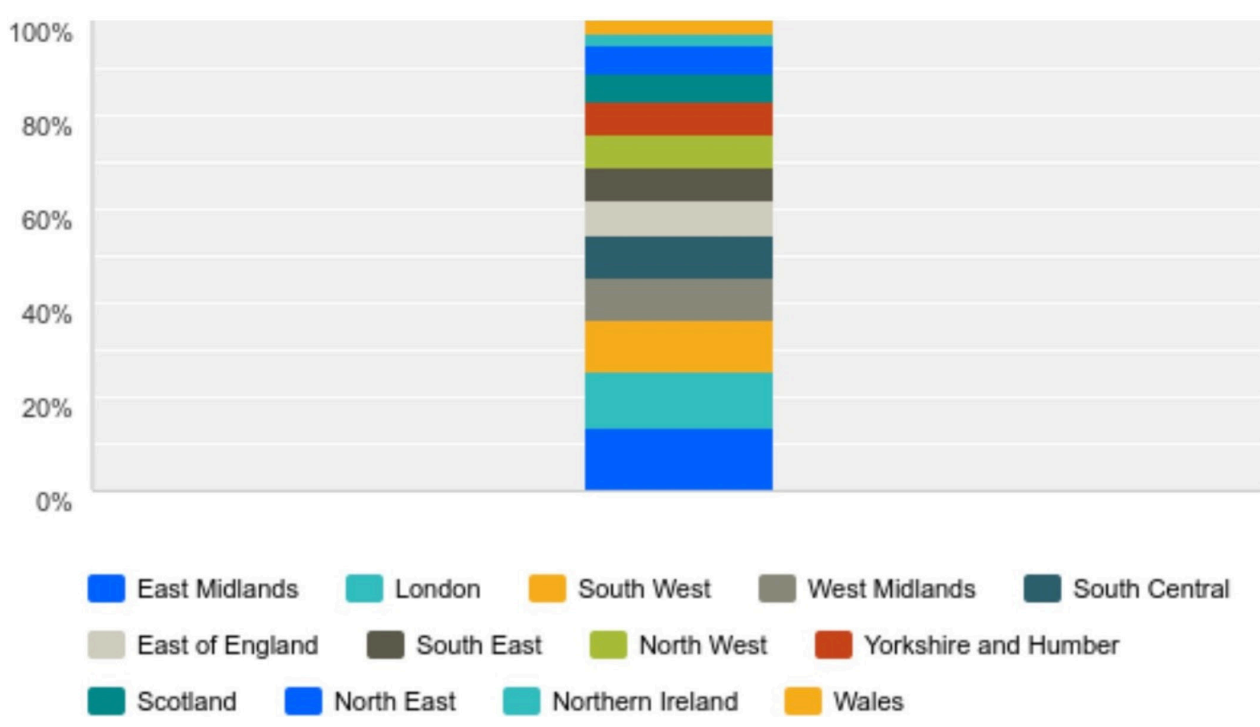

Figure 2 Chart showing data from question 1 - which region do you work in?

5. What diathermy modes do you use for polypectomy in the left side of colon?

(Level 1 pedunculated polypectomy, level 1 sessile polypectomy, level 2 pedunculated polypectomy, level 2 sessile polypectomy, level 3 polypectomy. Select between: mainly cutting, mainly coagulation, combination of cutting and coagulation, Endo Cut, cold snare (no diathermy), not applicable, or not sure).

6. What diathermy modes do you use for polypectomy in the right side of colon?

(Same selection options as question 5).

7. Do you use lower diathermy current settings for right side polypectomy versus left side? (Yes or No)

8. Do you feel confident in your knowledge and use of diathermy for polypectomy? (Yes or No)

The level classification of polypectomy is the same system used on JAG Endoscopy Training System online training logbook (see figure 1).

Initially the survey was distributed locally within the Midlands via a hyperlink sent via direct email to see if operators would return the completed survey. Once it was clear it was being returned completed by the majority who opened the survey, it was circulated widely. This was sent to endoscopists via BSG e-newsletter (after agreement with the BSG endoscopy section), BSG trainee e-newsletter, and ACGBI newsletter (after agreement with the ACGBI endoscopy section). Data were analysed using the SurveyMonkey custom filters and Microsoft Excel software.

\section{RESULTS}

Between February and October 2016, a total of 348 endoscopists started the survey, of which 250 completed the survey by answering all eight questions (71.8\%). The data analysis below demonstrates the data from the 250 completed survey responses.

\section{Question 1: which region do you work in?}

The respondents work in every region across the UK see figure 2 and table 1.

\section{Question 2: which endoscopy grade/role?}

The majority of respondents were consultant physician endoscopists (gastroenterologists) $(159,63.6 \%)$. There was a similar response rate from 36 consultant surgeon endoscopists (14.4\%) and 34 physician (gastroenterology) trainees $(13.6 \%)$. There were a small number of nurse endoscopists $(17,6.8 \%)$ and associate specialists/staff grade endoscopists $(4,1.6 \%)$ - see figure 3.

\section{Question 3: what are the endoscopy lists provided in a typical working month? \\ Of the respondents:}

- Two hundred and forty-seven (98.8\%) provided symptomatic lists every month, the vast majority $(222 / 247$, $89.9 \%$ ) providing at least one symptomatic list per week on average.

\begin{tabular}{lcc}
\hline Table 1 & Answer to question 1 & - which region do you work in? \\
\hline Region & $\mathrm{n}$ & \% of total \\
\hline East Midlands & 34 & 13.6 \\
\hline London & 30 & 12.0 \\
South-West & 27 & 10.8 \\
West Midlands & 23 & 9.2 \\
South Central & 22 & 8.8 \\
\hline East of England & 19 & 7.6 \\
South-East & 18 & 7.2 \\
\hline North-West & 17 & 6.8 \\
Yorkshire and Humber & 17 & 6.8 \\
Scotland & 16 & 6.4 \\
North-East & 14 & 5.6 \\
Northern lreland & 7 & 2.8 \\
Wales & 6 & 2.4 \\
\hline Total & 250 & 100 \\
\hline
\end{tabular}




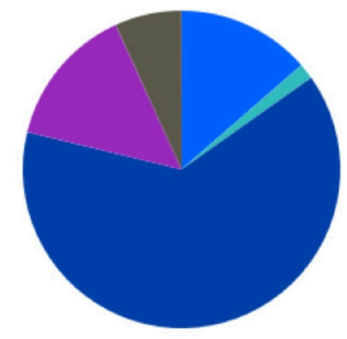

Physician Trainee - independent Associate Specialist / Staff Grade

Consultant Physician

Consultant Surgeon

Figure 3 Chart showing data from question 2 - which endoscopy grade/role?

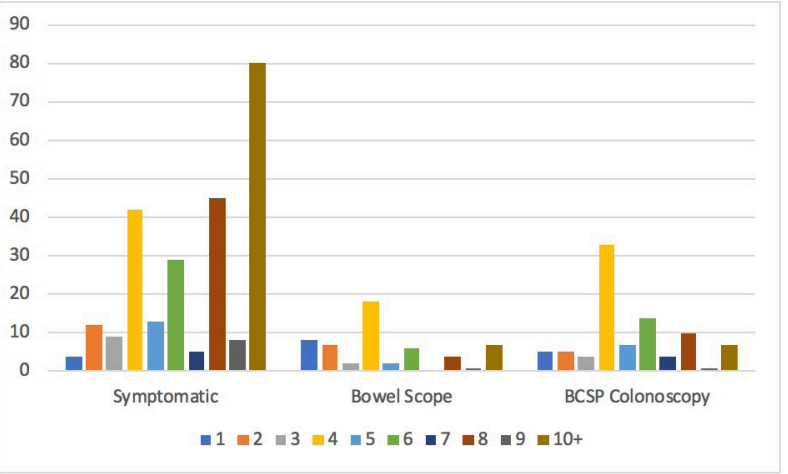

Figure 4 Chart showing data from question 3 - what are the endoscopy lists provided in a typical month? BCSP, Bowel Cancer Screening Programmes.

- Fifty-five (22.0\%) provided bowel scope lists every month, the majority $(69.1 \%)$ providing at least one list per week on average $(38 / 55)$.

- Ninety (36.0\%) provided BCSP colonoscopy lists every month, the vast majority $(84.4 \%)$ providing at least one list per week on average (76/90).

The full responses to question 3 are shown in table 2; the data on symptomatic, bowel scope and BCSP colonoscopy lists provided are represented in figure 4 .

\section{Question 4: what level of polypectomy do you undertake in a typical working month?}

Of the 250 respondents (see table 3 and figure 5):

- Two hundred and forty-three (97.2\%) performed regular level 1 polypectomy, 209 (83.6\%) doing one or more per week on average.
Table 3 Answer to question 4 - what level of polypectomy do you undertake in a typical working month?

\begin{tabular}{lllll}
\hline $\mathrm{n}$ & $0-1$ & $2-3$ & $4-6+$ & Total \\
\hline Level 1 polypectomy & 7 & 34 & 209 & 250 \\
(pedunculated and sessile) & $2.8 \%$ & $13.6 \%$ & $83.6 \%$ & \\
Level 2 polypectomy & 79 & 93 & 78 & 250 \\
(pedunculated and sessile) & $31.6 \%$ & $37.2 \%$ & $31.2 \%$ & \\
Level 3 polypectomy & 185 & 36 & 29 & 250 \\
& $74.0 \%$ & $14.4 \%$ & $11.6 \%$ & \\
\hline
\end{tabular}

- One hundred and seventy-one (68.4\%) performed regular level 2 polypectomy, 78 (31.2\%) doing one or more per week on average.

- Only 65 (26.0\%) performed regular level 3 polypectomy, 36 (14.4\%) doing less than one per week on average and $29(11.6 \%)$ doing one or more per week on average.

\section{Question 5: what diathermy modes do you use for polypectomy in the left side of colon?}

- Level 1 (1 cm in size or less) pedunculated polypectomy - 248 (99.2\%) described their technique: 46.4\% (116) use mainly coagulation current, $25.6 \%$ (64) use a combination of coagulation and cutting and 43 (17.2\%) use Endo Cut blended current.

- Level 1 sessile polypectomy - 248 (99.2\%) described their technique: 86 use a cold snare technique (34.4\%). A near equal distribution use mainly coagulation (49, $19.6 \%)$, a combination $(47,18.8 \%)$ and Endo Cut (46, $18.4 \%)$. Only 20 (8\%) use pure cutting current.

- Level 2 (up to $3 \mathrm{~cm}$ in size) pedunculated polypectomy $219(87.6 \%)$ described their technique: 96 (38.4\%) use mainly coagulation current, 77 (30.8\%) use a combination current, 42 (16.8\%) use Endo Cut.

- Level 2 sessile polypectomy - 209 (83.6\%) described their technique: 80 (32.0\%) use Endo Cut, 71 (28.4\%) use a combination current, $35(14.0 \%)$ use mainly coagulation current, $22(8.8 \%)$ use mainly cutting current.

- Level 3 polypectomy (EMR/large lesions with difficult access) - 153 (61.2\%) described their technique: 51 $(20.4 \%)$ and $50(20.0 \%)$ use combination current or Endo Cut, respectively; 27 (10.8\%) use mainly coagulation, 19 (7.6\%) use mainly cutting.

See table 4 for the full data set, and figure 6 for the chart representing these data.

\begin{tabular}{lcccccccccccc}
\hline Table 2 & Answer to question & - what are the endoscopy lists provided in a typical working month? \\
\hline Number of lists & 0 & 1 & 2 & 3 & 4 & 5 & 6 & 7 & 8 & 9 & $10+$ \\
\hline Symptomatic & 3 & 4 & 12 & 9 & 42 & 13 & 29 & 5 & 45 & 8 & 80 \\
Bowel scope & 195 & 8 & 7 & 2 & 18 & 2 & 6 & 0 & 4 & 1 & 7 \\
BCSP colonoscopy & 160 & 5 & 5 & 4 & 33 & 7 & 14 & 4 & 10 & 1 \\
\hline
\end{tabular}

BCSP, Bowel Cancer Screening Programmes. 


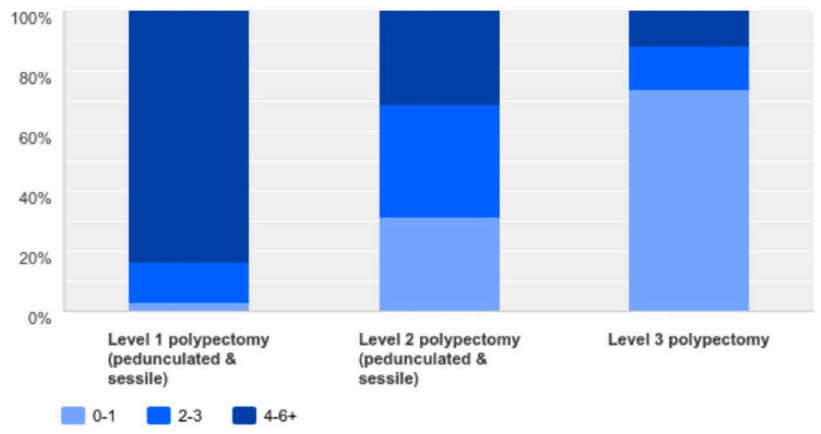

Figure 5 Chart showing data from question 4 - what level of polypectomy do you undertake in a typical working month? coagulation and cutting and 45 (18.0\%) use Endo Cut blended currents; 19 (7.6\%) use mainly cutting currents.

- Level 1 sessile polypectomy - 239 (95.6\%) described their technique: 108 use a cold snare technique (43.2\%); 40 (16.0\%) and 38 (15.2\%) use combination or Endo Cut, respectively; $28(11.2 \%)$ and $24(9.6 \%)$ use mainly cutting or mainly coagulation currents, respectively.

- Level 2 pedunculated polypectomy - 214 (85.6\%) described their technique: $82(32.8 \%)$ use a combination current, 74 (29.6\%) use mainly coagulation, 44 (17.6\%) use Endo Cut.

Level 2 sessile polypectomy - 203 (81.2\%) described their

Table 4 Answer to question 5 - what diathermy modes do you use for polypectomy in the left side of colon?

\begin{tabular}{|c|c|c|c|c|c|}
\hline $\begin{array}{l}\text { Mainly } \\
\text { coagulation }\end{array}$ & $\begin{array}{l}\text { Mainly } \\
\text { cutting }\end{array}$ & $\begin{array}{l}\text { Combination of } \\
\text { coagulation and }\end{array}$ & Endo Cut & $\begin{array}{l}\text { Cold snare } \\
\text { (no diathermy) }\end{array}$ & Not applicable Not sure \\
\hline
\end{tabular}

\begin{tabular}{|c|c|c|c|c|c|c|c|c|}
\hline $\begin{array}{l}\text { Level } 1 \\
\text { pedunculated }\end{array}$ & $\begin{array}{l}116 \\
46.4 \%\end{array}$ & $\begin{array}{l}11 \\
4.4 \%\end{array}$ & $\begin{array}{l}64 \\
25.6 \%\end{array}$ & $\begin{array}{l}43 \\
17.2 \%\end{array}$ & $\begin{array}{l}14 \\
5.6 \%\end{array}$ & $\begin{array}{l}2 \\
0.8 \%\end{array}$ & $\begin{array}{l}0 \\
0 \%\end{array}$ & 250 \\
\hline $\begin{array}{l}\text { Level } 1 \\
\text { sessile }\end{array}$ & $\begin{array}{l}49 \\
19.6 \%\end{array}$ & $\begin{array}{l}20 \\
8.0 \%\end{array}$ & $\begin{array}{l}47 \\
18.8 \%\end{array}$ & $\begin{array}{l}46 \\
18.4 \%\end{array}$ & $\begin{array}{l}86 \\
34.4 \%\end{array}$ & $\begin{array}{l}2 \\
0.8 \%\end{array}$ & $\begin{array}{l}0 \\
0 \%\end{array}$ & 250 \\
\hline $\begin{array}{l}\text { Level } 2 \\
\text { pedunculated }\end{array}$ & $\begin{array}{l}96 \\
38.4 \%\end{array}$ & $\begin{array}{l}2 \\
0.8 \%\end{array}$ & $\begin{array}{l}77 \\
30.8 \%\end{array}$ & $\begin{array}{l}42 \\
16.8 \%\end{array}$ & $\begin{array}{l}1 \\
0.4 \%\end{array}$ & $\begin{array}{l}31 \\
12.4 \%\end{array}$ & $\begin{array}{l}1 \\
0.4 \%\end{array}$ & 250 \\
\hline $\begin{array}{l}\text { Level } 2 \\
\text { Sessile }\end{array}$ & $\begin{array}{l}35 \\
14.0 \%\end{array}$ & $\begin{array}{l}22 \\
8.8 \%\end{array}$ & $\begin{array}{l}71 \\
28.4 \%\end{array}$ & $\begin{array}{l}80 \\
32.0 \%\end{array}$ & $\begin{array}{l}1 \\
0.4 \%\end{array}$ & $\begin{array}{l}41 \\
16.4 \%\end{array}$ & $\begin{array}{l}0 \\
0 \%\end{array}$ & 250 \\
\hline Level 3 & $\begin{array}{l}27 \\
10.8 \%\end{array}$ & $\begin{array}{l}19 \\
7.6 \%\end{array}$ & $\begin{array}{l}51 \\
20.4 \%\end{array}$ & $\begin{array}{l}50 \\
20.0 \%\end{array}$ & $\begin{array}{l}0 \\
0 \%\end{array}$ & $\begin{array}{l}97 \\
38.8 \%\end{array}$ & $\begin{array}{l}6 \\
2.4 \%\end{array}$ & 250 \\
\hline
\end{tabular}

Question 6: what diathermy modes do you use for polypectomy in the right side of colon?

- Level 1 pedunculated polypectomy - 240 (96.0\%) described their technique: $31.2 \%$ (78) use mainly coagulation current, $21.6 \%$ (54) use a combination of technique: $72(28.8 \%)$ use Endo Cut, 65 (26.0\%) use a combination current, $33(13.2 \%)$ use mainly cutting current, 27 (10.8\%) use mainly coagulation current.

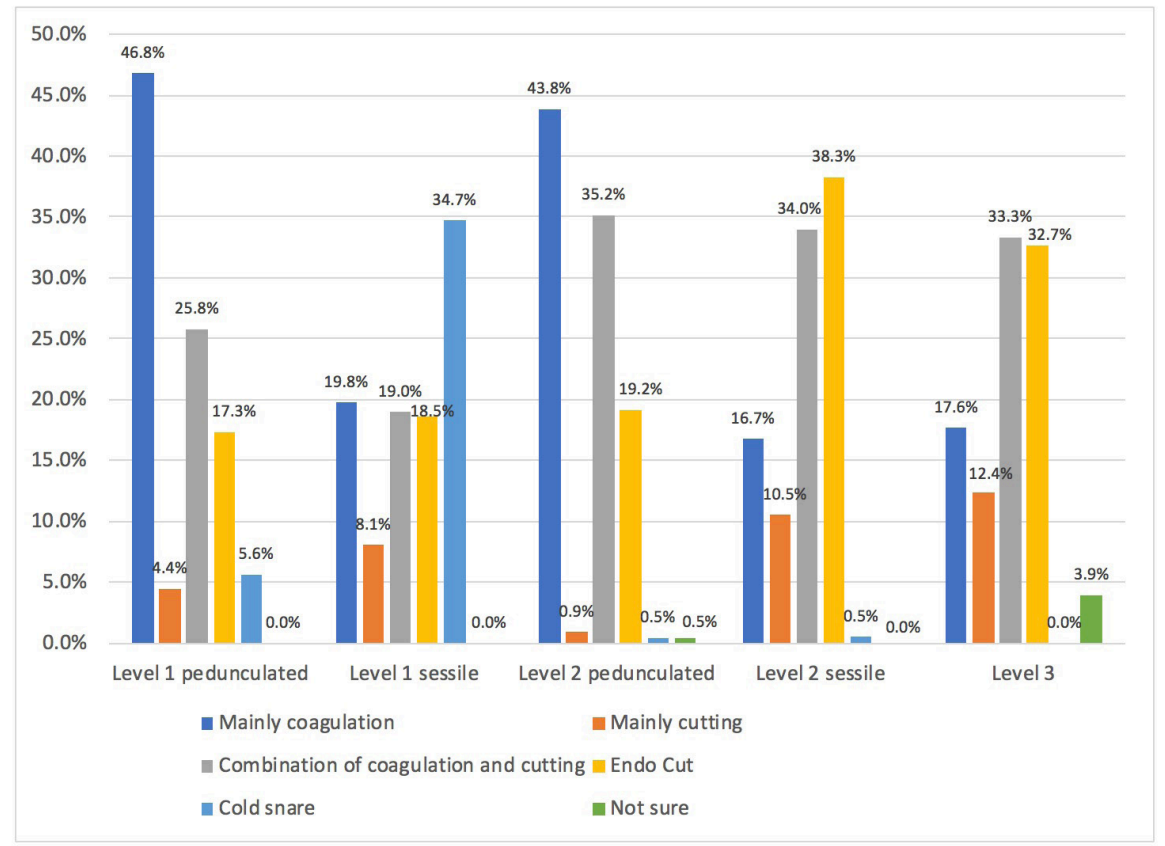

Figure 6 Chart showing data from question 5 - what diathermy modes do you use for polypectomy in the left side of colon? 
Table 5 Answer to question 6 - what diathermy modes do you use for polypectomy in the right side of colon?

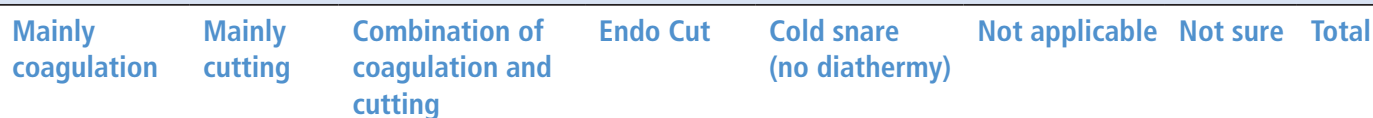

\begin{tabular}{lllllllll}
\hline Level 1 & 78 & 19 & 54 & 45 & 41 & 10 & 3 & 250 \\
pedunculated & $31.2 \%$ & $7.6 \%$ & $21.6 \%$ & $18.0 \%$ & $16.4 \%$ & $4.0 \%$ & $1.2 \%$ & 1 \\
Level 1 & 24 & 28 & 40 & 38 & 108 & 11 & 250 \\
sessile & $9.6 \%$ & $11.2 \%$ & $16.0 \%$ & $15.2 \%$ & $43.2 \%$ & $4.4 \%$ & $0.4 \%$ & 2 \\
Level 2 & 74 & 8 & 82 & 44 & 4 & 36 & 250 \\
pedunculated & $29.6 \%$ & $3.2 \%$ & $32.8 \%$ & $17.6 \%$ & $1.6 \%$ & $14.4 \%$ & $0.8 \%$ & 2 \\
Level 2 & 27 & 33 & 65 & 72 & 4 & 47 & 2 & 250 \\
Sessile & $10.8 \%$ & $13.2 \%$ & $26.0 \%$ & $28.8 \%$ & $1.6 \%$ & $18.8 \%$ & $0.8 \%$ & 6 \\
Level 3 & 23 & 21 & 43 & 54 & 1 & 102 & 250 \\
& $9.2 \%$ & $8.4 \%$ & $17.2 \%$ & $21.6 \%$ & $0.4 \%$ & $40.8 \%$ & $2.4 \%$ \\
\hline
\end{tabular}

Level 3 polypectomy - 148 (59.2\%) described their technique: $54(21.6 \%)$ and $43(17.2 \%)$ use Endo Cut or combination current, respectively; 23 (9.2\%) use mainly coagulation, $21(8.4 \%)$ use mainly cutting.

See table 5 for the full data set, and figure 7 for the chart representing these data.

\section{Question 7: do you use lower diathermy current settings for right side polypectomy versus left side?}

There were 204 out of 250 (81.6\%) who answered this question 'Yes', 46 (18.4\%) answered 'no' (figure 8).

\section{Question 8: do you feel confident in your knowledge and use of diathermy for polypectomy?}

There were 208 out of $250(83.2 \%)$ who answered this question 'Yes', 42 (16.8\%) answered 'no' (figure 9).

\section{Subanalysis}

When filtering the responses for those who were confident in their knowledge and use of diathermy in polypectomy (answered 'Yes' to question 8):
> Only 17 (8.17\%) were trainees - dropped from 13.6\% of all respondents.

- Use of diathermy for polypectomy in left and right colon is similar to 'all respondents' analysis.

- Similar numbers of lists and polypectomies to 'all respondents'.

When filtering the responses for those who performed level 3 polypectomy either 2-3 or $4-6+$ times in a typical month (question 4) - 65/250 respondents $(26.0 \%)$ :

- Sixty-two (95.38\%) were confident in knowledge and use of diathermy in polypectomy.

- Minimal numbers using mainly cutting current for polypectomy - less than in 'all respondents' analysis.

\section{DISCUSSION}

The challenge of a questionnaire-based survey is for it to capture enough detail to give a meaningful analysis, and also to be short enough so that once the survey has started, the majority of respondents answer all

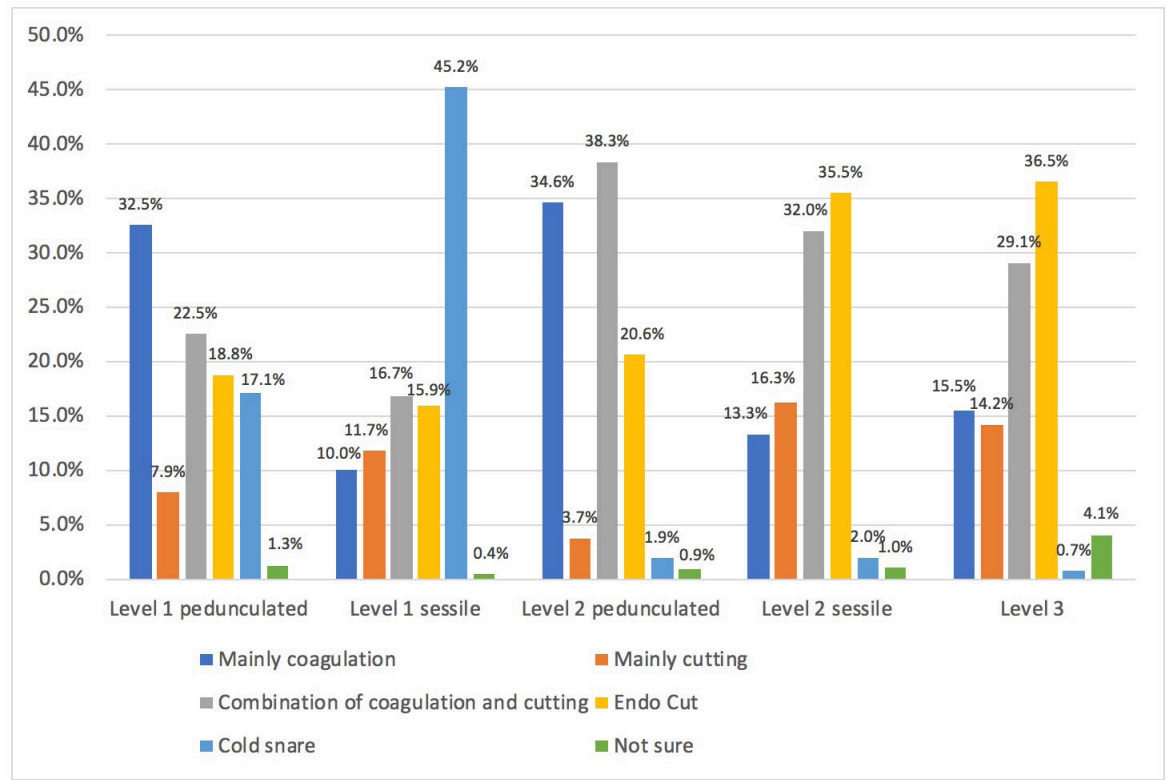

Figure 7 Chart showing data from question 6 - what diathermy modes do you use for polypectomy in the right side of colon? 


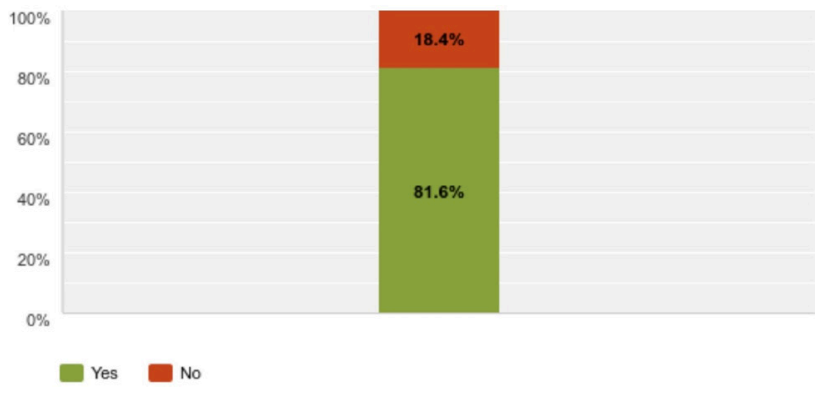

Figure 8 Chart showing data for answers to question 7 - do you use lower diathermy current settings for right side polypectomy versus left side?

the questions to complete the survey. This survey has achieved a high completion rate of $71.8 \%$ (250 out of 348). This makes it the largest published survey on diathermy practice for colonic polypectomy. The data are comprised from responses from every region of the UK and across the grades and specialties of endoscopists. The endoscopists have regular lists and all perform regular polypectomy, $83.6 \%$ perform level 1 polypectomy $>1$ per week on average, though the numbers performing level 2 and level 3 polypectomy at least one per week on average drop markedly (as one would expect).

The published guidelines on diathermy use for polypectomy are far from comprehensive. The recommended use of cold snare polypectomy for sub- $10 \mathrm{~mm}$ (level 1) polyps is high for sessile polyps: left colon polypectomy $34.7 \%$, right colon $45.2 \%$. For pedunculated level 1 polyps, cold snare polypectomy rates drop markedly: left colon polypectomy 5.6\%, right colon $17.1 \%$. The most popular diathermy setting for pedunculated level 1 polypectomy is mainly coagulation: left colon polypectomy $46.8 \%$, right colon $32.5 \%$.

The recommendation from the BSG guideline that for large non-pedunculated colorectal polyps suggests 'that a prolonged pure coagulation current should be avoided owing to an increased risk of delayed post-polypectomy bleeding and thermal tissue injury.' ESGE guidance recommends 'against using low power coagulation current for EMR because of the increased risk of post-procedural bleeding.' Reassuringly, the rate of

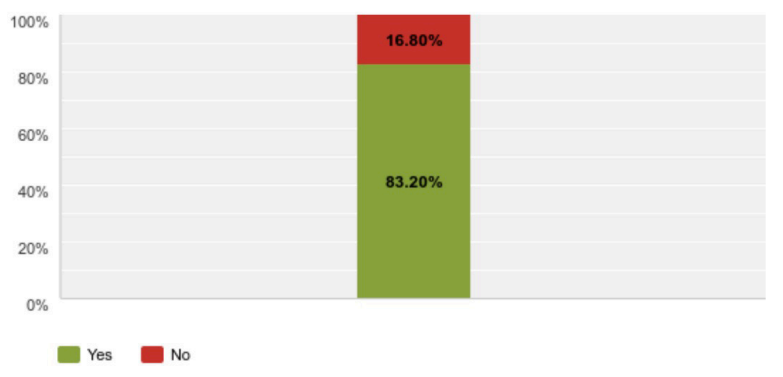

Figure 9 Chart showing data for answers to question 8 - do you feel confident in your knowledge and use of diathermy for polypectomy?

\section{Significant of this study}

What is already known on this topic

- Two large surveys have been published on this subject, showing a wide variance in diathermy practice for colonic polypectomy.

What this study adds

- This is the largest published survey on this subject.

- Despite the increasingly regulated and protocoled manner of modern endoscopic practice, there is a wide variation of diathermy practice for colonic polypectomy within the UK, this makes training a challenge and could lead to adverse patient outcomes.

\section{How might it impact on clinical practice in the foreseeable future \\ - Recognising variation in practice should prompt stakeholders of endoscopy to issue guidance for best practice, and training for future endoscopists.}

combination diathermy; combination of coagulation and cutting current, or Endo Cut level 2 sessile polyps, and level 3 polyps, is high:

- Left colon - - level 2 sessile polypectomy $72.3 \%$, level 3 polypectomy $66.0 \%$.

- Right colon - - level 2 sessile polypectomy $67.5 \%$, level 3 polypectomy $65.6 \%$.

However, use of pure coagulation current is at a concerningly high rate:

- Left colon - - level 2 sessile polypectomy 16.7\%, level 3 polypectomy $17.6 \%$.

- Right colon - - level 2 sessile polypectomy 13.3\%, level 3 polypectomy $15.5 \%$.

The ESGE guidance recommends 'against using pure cutting current for pedunculated polypectomy because of an increased risk of intraprocedural bleeding.' Reassuringly, rates of mainly cutting current are low:

- Left colon - level 1 pedunculated polypectomy 4.4\%, level 2 pedunculated $8.1 \%$.

- Right colon - level 1 pedunculated polypectomy 7.9\%, level 2 pedunculated $11.7 \%$.

The data from this large survey show that cold snare polypectomy for small polyps is reasonably popular though traditional setting of pure coagulation current is the most popular for pedunculated polypectomy. Mainly cutting current is rarely used for pedunculated polypectomy which is reassuring - minimising the risk of intraprocedural bleeding. A combination of coagulation and cutting current, or Endo Cut is the most popular diathermy setting for larger (sessile) polypectomy, but worryingly a small pocket of practice of using mainly coagulation current persists for these polyps - increasing the risk of thermal colonic injury.

The vast majority of operators $(81.6 \%)$ state they use a lower current setting for right colonic 
polypectomy, and feel confident in their knowledge and use of diathermy (83.2\%). While this is promising, this rate for both should ideally be closer to $100 \%$.

This variation in practice shows that the evidence base needs reinforcing with further studies so more concrete guidance on diathermy for colonic polypectomy can be published and disseminated. There is also an issue of training, what is being taught to trainees? In the era of high-quality evidence-based lower gastrointestinal endoscopy practice with standardisation of practice, diathermy for polypectomy is the poor relative which could lead to adverse patient outcomes.

Acknowledgements We are grateful to the BSG endoscopy section, BSG trainee section and ACGBI endoscopy section for circulating the survey via newsletter and/or email. We also thank all respondents to the survey from across the UK.

Contributors AMV and APC designed the survey. AMV analysed the data and wrote the manuscript. APC reviewed the manuscript.

Funding The authors have not declared a specific grant for this research from any funding agency in the public, commercial or not-for-profit sectors.

Competing interests None declared.

Patient consent Not required.

Provenance and peer review Not commissioned; externally peer reviewed.

\section{REFERENCES}

1 Ngu WS, Bevan R, Tsiamoulos ZP, et al. Improved adenoma detection with Endocuff Vision: the ADENOMA randomised controlled trial. Gut 2018.

2 Kim JS, Lee BI, Choi H, et al. Cold snare polypectomy versus cold forceps polypectomy for diminutive and small colorectal polyps: a randomized controlled trial. Gastrointest Endosc 2015;81:741-7.
3 Efthymiou M, Taylor AC, Desmond PV, et al. Biopsy forceps is inadequate for the resection of diminutive polyps. Endoscopy 2011;43:312-6.

4 Horiuchi A, Nakayama Y, Kajiyama M, et al. Removal of small colorectal polyps in anticoagulated patients: a prospective randomized comparison of cold snare and conventional polypectomy. Gastrointest Endosc 2014;79:417-23.

5 Ichise Y, Horiuchi A, Nakayama Y, et al. Prospective randomized comparison of cold snare polypectomy and conventional polypectomy for small colorectal polyps. Digestion 2011;84:78-81.

6 Paspatis GA, Tribonias G, Konstantinidis K, et al. A prospective randomized comparison of cold vs hot snare polypectomy in the occurrence of postpolypectomy bleeding in small colonic polyps. Colorectal Dis 2011;13:e345-8.

7 Chino A, Karasawa T, Uragami N, et al. A comparison of depth of tissue injury caused by different modes of electrosurgical current in a pig colon model. Gastrointest Endosc 2004;59:374-9.

8 Parra-Blanco A, Kaminaga N, Kojima T, et al. Colonoscopic polypectomy with cutting current: is it safe? Gastrointest Endosc 2000;51:676-81.

9 Kim HS, Kim TI, Kim WH, et al. Risk factors for immediate postpolypectomy bleeding of the colon: a multicenter study. Am J Gastroenterol 2006;101:1333-41.

10 Tokar JL, Barth BA, Banerjee S, et al. Electrosurgical generators. Gastrointest Endosc 2013;78:197-208.

11 Rutter MD, Chattree A, Barbour JA, et al. British Society of Gastroenterology/Association of Coloproctologists of Great Britain and Ireland guidelines for the management of large non-pedunculated colorectal polyps. Gut 2015;64:1847-73.

12 Ferlitsch M, Moss A, Hassan C, et al. Colorectal polypectomy and endoscopic mucosal resection (EMR): European Society of Gastrointestinal Endoscopy (ESGE) Clinical Guideline. Endoscopy 2017;49:270-97.

13 Singh N, Harrison M, Rex DK. A survey of colonoscopic polypectomy practices among clinical gastroenterologists. Gastrointest Endosc 2004;60:414-8.

14 Carter D, Beer-Gabel M, Zbar A, et al. A survey of colonoscopic polypectomy practice amongst Israeli gastroenterologists. Ann Gastroenterol 2013;26:135-40. 